\title{
Quality Evaluation of Granulated Blast Furnace Slag Sand Via Acid Immersion and Freeze-Thaw Tests
}

\author{
Takaya Kawato $^{1}$ and Isao Kurashige ${ }^{2}$ \\ ${ }^{1,2}$ Central Research Institute of Electric Power Industry, Civil Engineering Research Laboratory, \\ Nuclear Fuel Cycle Backend Research Center, 1646 Abiko, Abiko-shi, Chiba, 270-1194 Japan. \\ ${ }^{1}$ t-kawato@criepi.denken.or.jp_2 kurasige@criepi.denken.or.jp
}

\begin{abstract}
In recent years, the use of granulated blast furnace slag (GBFS) sand as fine aggregate in concrete has been increasingly discussed from the viewpoint of environmental impact reduction and effective utilization of by-products in Japan. The various physical properties of concrete with GBFS sand, such as the compressive strength, drying shrinkage, and carbonation, were evaluated. Especially, it was demonstrated that GBFS sand can modify the hardened cement paste around it owing to the reaction of amorphous phase in the sand. Moreover, its resistance to sulfuric acid is considered to be as excellent as that of BFS powder. Therefore, in this study, we attempted to evaluate the performance of GBFS sand using a freeze-thaw (F-T) and acid immersion tests. Consequently, it was found that GBFS sand mortar had a significantly higher resistance to $F-T$ and sulfuric acid than crushed sand mortar. In addition, it improved the resistance to freezing and thawing by prolonged curing. In our experiments, the resistance of GBFS sand mortar to sulfuric acid was measured to be approximately four times higher than that of crushed sand mortar. In contrast, in the case of nitric acid, the ratio was measured to be only two times higher. From the above results, it was concluded that the performance of GBFS sand can be easily judged by F-T and sulfuric acid immersion tests.
\end{abstract}

Keywords: Blast Furnace Slag, Quality Evaluation, Resistance Test, Acid, Freeze-Thaw.

\section{Introduction}

From the viewpoint of environmental protection and depletion of natural resources, the use of artificial aggregates and by-products are promoted for concrete aggregate. In Japan, the JIS standard for coarse aggregate for concrete of blast furnace slag was established in 1977 and the standard for blast furnace slag fine aggregate was added in 1981 (JIS A 5011-1). However, the use of blast furnace slag as aggregate remains at approximately $0.7 \%$ of the aggregate for concrete because blast furnace slag aggregate has a poor track record and its quality is not reliable enough.

If the utilization rate of GBFS sand is improved, the environmental footprint can be reduced and a high durability concrete structure can be constructed. Therefore, the reactivity of GBFS sand is appropriately evaluated and its performance is incorporated into the concrete performance design to improve reliability. When GBFS sand is used for concrete, it is known to improve the neutralization resistance, F-T resistance, and permeability resistance to chloride ion and sulfuric acid, and reduce the drying shrinkage (e.g., Ayano et al., 2014; Patra et al., 2018; Takahashi et al., 2018). The performance of GBFS sand is determined by the reactivity depending on the composition and manufacturing method.

In this study, to establish the method for evaluating the reactivity of GBFS sand, we 
examined the GBFS sand quality evaluation test methods and test conditions. When GBFS sand is used for concrete, the interface between the aggregate and cement paste is modified. To measure the reactivity of interface between GBFS sand and cement paste, F-T test was conducted in salt-water. In addition, acid immersion test was performed to measure the reactivity of GBFS sand with acid. Crushed sand was used for the comparison with GBFS sand.

\section{Experiments}

\subsection{F-T Test in Salt Water Using Small Mortar Pieces}

\subsubsection{F-T test process}

- Using a diamond cutter, from a $40 * 40 * 160 \mathrm{~mm}$ mortar cured under water with a temperature of $20^{\circ} \mathrm{C}$ until the age of seven days, quarry test specimens that is $10 \pm 2 \mathrm{~mm}$ cube on all sides.

- Quarried specimens were cured in water up to the planned age.

- Test solution was prepared by adding 5 mass \% sodium chloride.

- Moisture was wiped from the surface of the specimens cured until the planned age, the seven pieces were formed into a set, and the total mass $\left(\mathrm{m}_{0}\right)$ was measured.

- A set of specimens and $10 \pm 0.05$ times the test solution was placed in a 200-300 mL test container, its lid wascapped, and it was left in the F-T apparatus (Figure 1.).

- The F-T cycle consisted

- At the end of 28 cydles of F-T,

were wiped off and the

- Mass residual rate $(\mathbb{R})$ was evaluated using the

$\mathrm{R}=\frac{m_{t}}{\mathrm{~m}} \times 100$

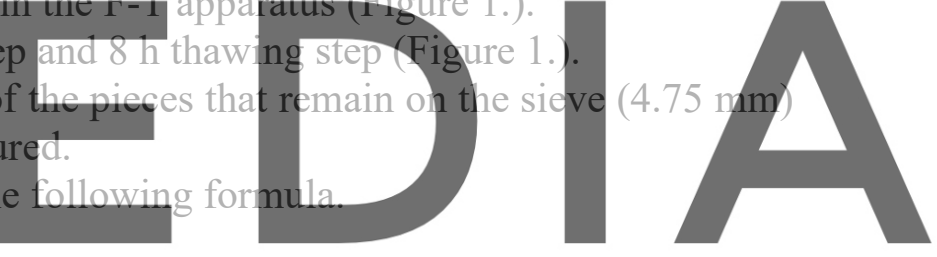

(1)

Register for free at https//www.scipedia.como to download the version without the watermark Where,
R: Mass residual rate after t cycle (\%)
$m_{0}$ : Initial mass $(g)$
$m_{t}:$ Mass after t cycle $(g)$

\subsubsection{F-T test conditions}

Table 1. shows the conditions for the F-T test. We examined the effects of the curing period and test period on the F-T evaluation test in salt-water. Furthermore, to investigate leaching during the test, it was compared with a test system using a saturated aqueous solution of calcium hydroxide $(\mathrm{CH})$ as a solvent. 
Table 1. Conditions for the F-T test.

\begin{tabular}{|c|c|c|c|c|c|c|c|}
\hline Symbol & Cement & Fine aggregate & W/C & $\mathrm{S} / \mathrm{C}$ & Curing & Test period & Solution \\
\hline 14B & \multirow{8}{*}{ OPC } & BFS & \multirow{8}{*}{0.5} & \multirow{8}{*}{2.25} & \multirow{4}{*}{$14 d$} & \multirow{4}{*}{ (7cycles) } & \multirow{2}{*}{$5 \% \mathrm{NaCl}$} \\
\hline $14 S$ & & $S$ & & & & & \\
\hline $14 \mathrm{~B}+\mathrm{CH}$ & & BFS & & & & & $5 \% \mathrm{NaCl}$ \\
\hline $14 \mathrm{~S}+\mathrm{CH}$ & & $S$ & & & & & $+\mathrm{CH}$ sat.aq. \\
\hline 28B & & BFS & & & \multirow{4}{*}{$28 d$} & \multirow{4}{*}{ 28cycles } & \\
\hline $28 S$ & & $S$ & & & & & $5 \%$ Ivacl \\
\hline $28 \mathrm{~B}+\mathrm{CH}$ & & BFS & & & & & $5 \% \mathrm{NaCl}$ \\
\hline $28 \mathrm{~S}+\mathrm{CH}$ & & $S$ & & & & & $+\mathrm{CH}$ sat.aq. \\
\hline
\end{tabular}
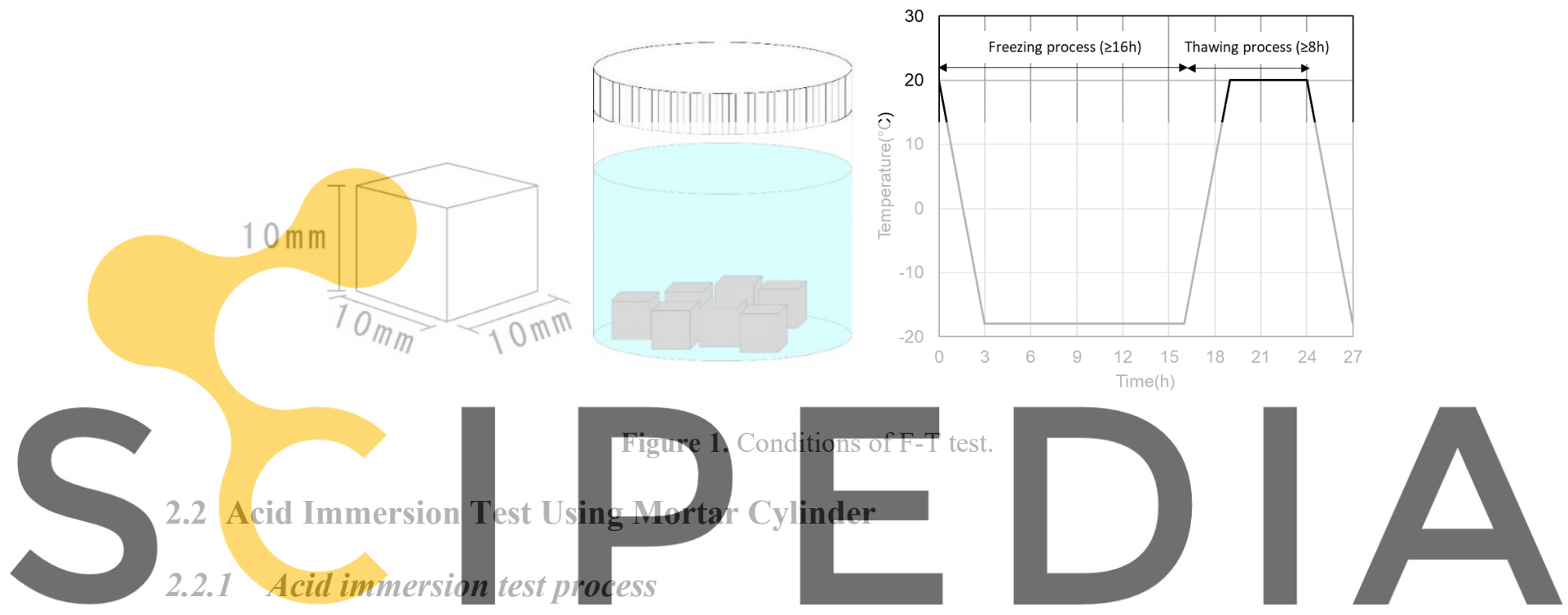

- Cylinder specimens (diameter $=50 \mathrm{~mm}\left(\mathrm{D}_{0}\right)$, height $=100 \mathrm{~mm}$ ) cured up to 28 days in water

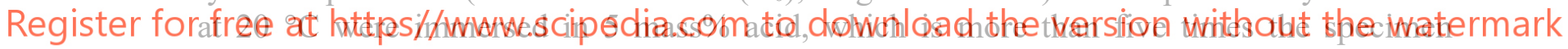
volume.

- Complete immersion of the specimen was confirmed, its container was covered, and left at $20 \pm 2{ }^{\circ} \mathrm{C}$. Figure 2 . shows the conditions for the acid immersion test.

- In case of "with" exchange, all acid solutions were replaced every seven days, and the upper and lower sides of the specimen were inverted each time.

- After immersion for 56 days, a cut was made on the center of the remaining specimen height.

- Phenolphthalein solution was sprayed on the cut surface and the diameter of the colored part (D56) was measured.

- Evaluation is based on the erosion depth (Ys) derived from the following equation.

$$
\mathrm{Ys}=\frac{\left(D_{0}-D_{56}\right)}{2}
$$

Where,

$Y_{s}:$ Erosion depth (mm)

$D_{0}$ : Initial specimen diameter ( $\mathrm{mm}$ )

D56: Diameter of non-neutralization area after 56 days (mm) 


\subsubsection{Acid immersion test condition}

For the acid immersion test, we investigated sulfuric acid and nitric acid. In addition, we investigated the possibility of reducing acid waste and the number of test processes by comparing the "with" and "without" test solution exchanges. Table 2. lists the conditions for the acid immersion test.

Table 2 Conditions for the acid immersion test.

\begin{tabular}{|c|c|c|c|c|c|c|c|c|c|}
\hline Symbol & Cement & Fine aggregate & $\mathrm{W} / \mathrm{C}$ & $\mathrm{S} / \mathrm{C}$ & Curing & Test period & Solution & Solition exchange & Liquid-solid ratio \\
\hline B-S & \multirow{8}{*}{ OPC } & BFS & \multirow{8}{*}{0.3} & \multirow{8}{*}{1.7} & \multirow{8}{*}{$28 d$} & \multirow{8}{*}{$56 d$} & \multirow{4}{*}{$5 \% \mathrm{H}_{2} \mathrm{SO}_{4}$} & \multirow{2}{*}{ with } & \multirow{2}{*}{$\begin{array}{c}5 \text { times or more } \\
(7.0)\end{array}$} \\
\hline S-S & & $S$ & & & & & & & \\
\hline $\mathrm{B}-\mathrm{S}(\mathrm{N} / \mathrm{A})$ & & BFS & & & & & & \multirow{2}{*}{ without } & \multirow{2}{*}{22.5} \\
\hline S-S(N/A) & & $S$ & & & & & & & \\
\hline $\mathrm{B}-\mathrm{N}$ & & BFS & & & & & \multirow{4}{*}{$5 \% \mathrm{HNO}_{3}$} & \multirow{2}{*}{ with } & \multirow{2}{*}{$\begin{array}{c}5 \text { times or more } \\
(7.0)\end{array}$} \\
\hline S-N & & $S$ & & & & & & & \\
\hline$B-N(N / A)$ & & BFS & & & & & & \multirow{2}{*}{ without } & \multirow{2}{*}{22.5} \\
\hline S-N(N/A) & & S & & & & & & & \\
\hline
\end{tabular}
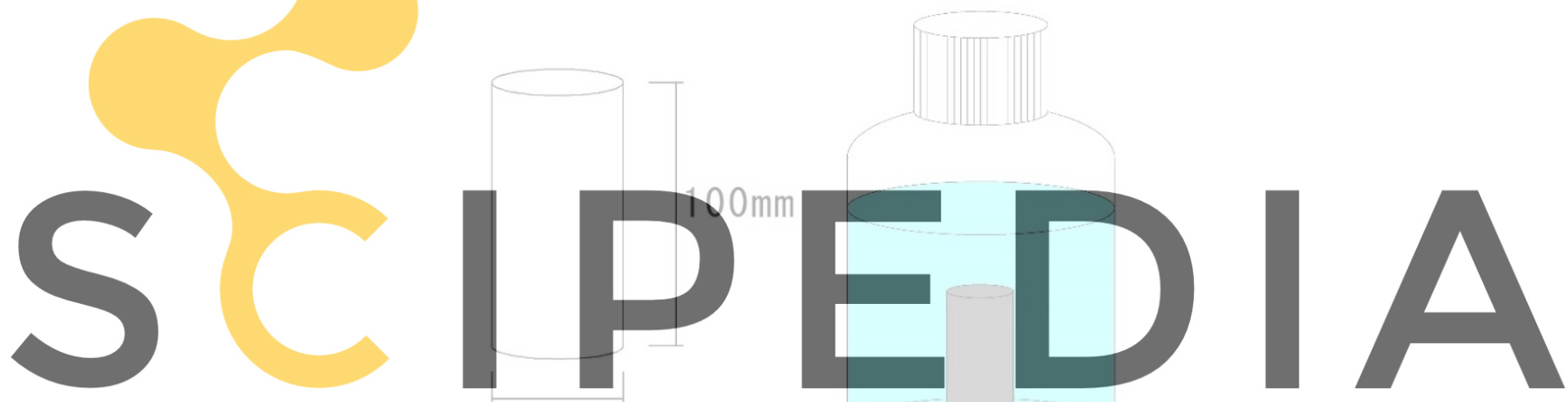

Register for free at https//www.scipedia.com to download the version without the watermark

Figure 2. Conditions for the acid immersion test.

\section{Results and Discussion}

\subsection{F-T Test Results and Discussion}

Figure 3. shows the effect of curing days.

Figure 4. shows the effect of leaching.

Table 3. shows the $\mathrm{pH}$ of the solution after the F-T test.

\subsubsection{Difference in number of curing days}

Compared to crushed sand mortar, GBFS mortar clearly demonstrated the difference in mass residual rate for a curing period of 28 days. To evaluate the quality potential of GBFS, a longer curing period was considered necessary.

\subsubsection{Difference in test period}

GBFS with 28 days of curing could evaluate the quality even at the end of 28 cycles; however, 
under other conditions, the mass residual rate was extremely low at the end of 14 cycles, making it impossible to evaluate the quality of the aggregate. When the residual mass of the mortar began to decrease, seven cycles were considered suitable for evaluation.

\subsubsection{Effect of leaching}

F-T using salt-water requires higher F-T resistance than when fresh water is used. Focusing on the difference in test solution during the seven cycles of 14-day curing, $5 \% \mathrm{NaCl}$ showed a smaller value for $5 \% \mathrm{NaCl}+\mathrm{CH}$ sat.aq. (11\% for GBFS, $13 \%$ for crushed sand). From these results, it is considered that $5 \% \mathrm{NaCl}$ evaluates the quality of GBFS in the state of adding the influence of leaching as well as F-T. From Table 3., the initial value of $5 \% \mathrm{NaCl}$ is $\mathrm{pH}=7.22$; however, after testing both GBFS and crushed sand, their $\mathrm{pH}$ exceeded a value of 12 . In contrast, the initial value of $5 \% \mathrm{NaCl}+\mathrm{CH}$ sat.aq. was $\mathrm{pH}=12.95$ and 12 or more after the test. From the result, it was surmised that leaching is suppressed in $5 \% \mathrm{NaCl}+\mathrm{CH}$ sat.aq.
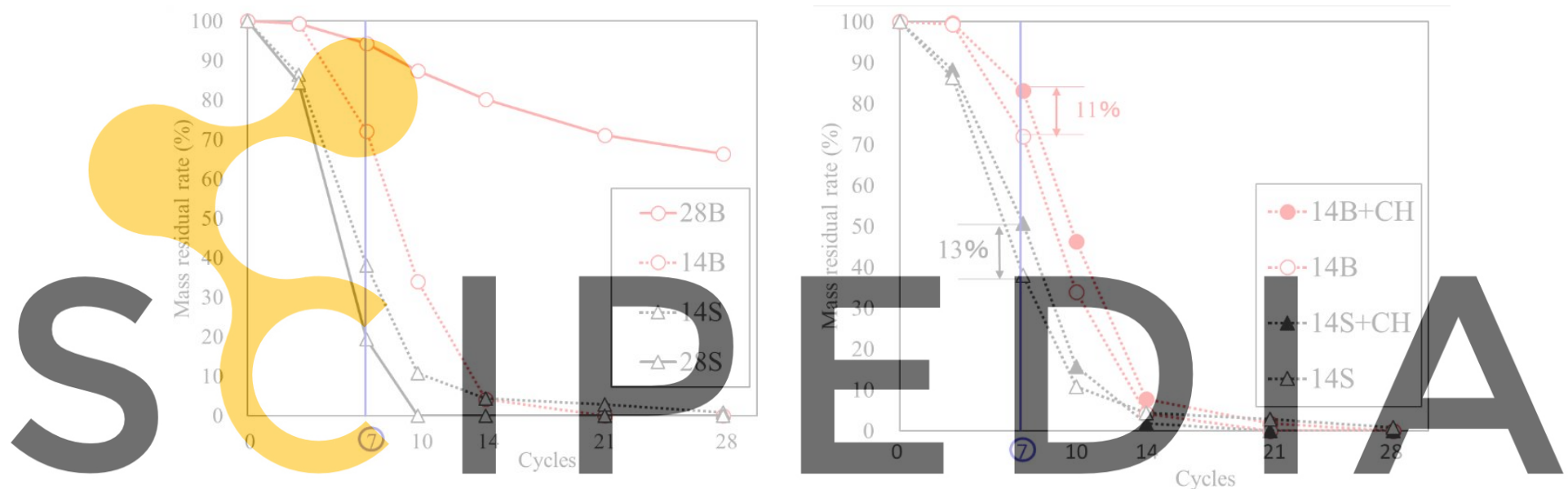

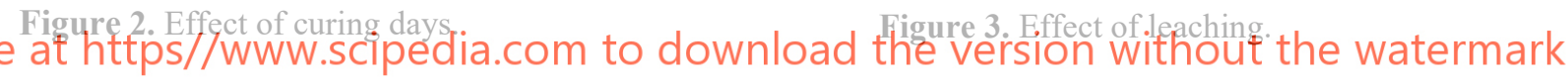

Table 1. pH of the solution after the F-T test.

\begin{tabular}{|c|c|c|}
\hline Symbol & $5 \% \mathrm{NaCl}$ & $5 \% \mathrm{NaCl}+\mathrm{CH}$ sat.aq. \\
\hline Initial & 7.22 & 12.95 \\
\hline BFS-14 & 12.55 & 12.61 \\
\hline CS-14 & 12.45 & 12.54 \\
\hline BFS-28 & 12.87 & 12.95 \\
\hline CS-28 & 12.93 & 12.99 \\
\hline
\end{tabular}

\subsection{Acid Immersion Test Results and Discussion}

Figure 5. shows the results of acid immersion test.

Figure 6. shows the state after the acid immersion test (no-exchange).

Figure 7. shows the shape of specimen after the acid immersion test about solution exchange.

\subsubsection{Effect of liquid exchange}

The depth of erosion in the sulfuric acid immersion test was reduced by $1.0 \mathrm{~mm}(28 \%)$ and 
$4.5 \mathrm{~mm}(34 \%)$ for GBFS and crushed sand, respectively, when the liquid was not changed because the total amount of solution in contact with the specimen during the test period was as small as 22.5 in "without replacement," as compared to 56 (7.0 times $\times 8$ times) in "with replacement," per liquid-solid ratio. In addition, when the solution was changed, the difference in fine aggregate performance was more pronounced. The erosion depth in the nitric acid immersion test was also confirmed to decrease by $3.0 \mathrm{~mm}(48 \%)$ for GBFS and 3.2 $\mathrm{mm}(29 \%)$ for crushed sand. This is also thought to be due to the amount of solution in contact.

\subsubsection{Difference between sulfuric acid and nitric acid}

GBFS erosion depth in sulfuric acid immersion test decreased to $27 \%$ in comparison to crushed sand. In GBFS, calcium and magnesium were eluted by the reaction of sulfuric acid and aggregate; thus, the expansion force of the generated dihydrate gypsum was relaxed and deposited on the surface without peeling off, which is considered to suppress erosion (Jariyathitipong et al., 2013). In this study as well, the suppression of peeling shown in Figure 6. was confirmed. In contrast, in the nitric acid immersion test, the erosion depth of GBFS only decreased to $58 \%$ in comparison to crushed sand. Unlike dihydrate gypsum, calcium nitrate is known to have very high solubility, which prevents the reactants from precipitating, and the calcium elution is excellent; thus, erosion proceeds (Tanaka et al., 2008). This study also showed the melting of calcium and softening of the surface layer.

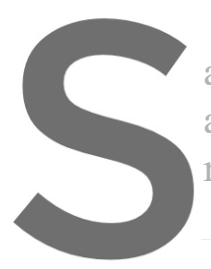

In nitric acid erosion

acid, the influence of h also added. Therefore, reduced.

16
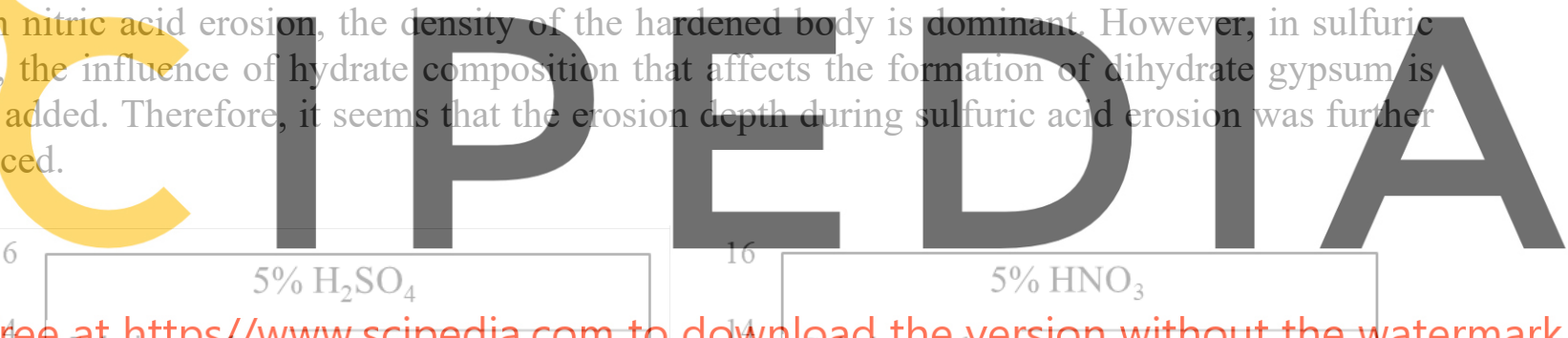

Register for free atuhtatpst dawgww.scipedia.com to download the version without the watermark
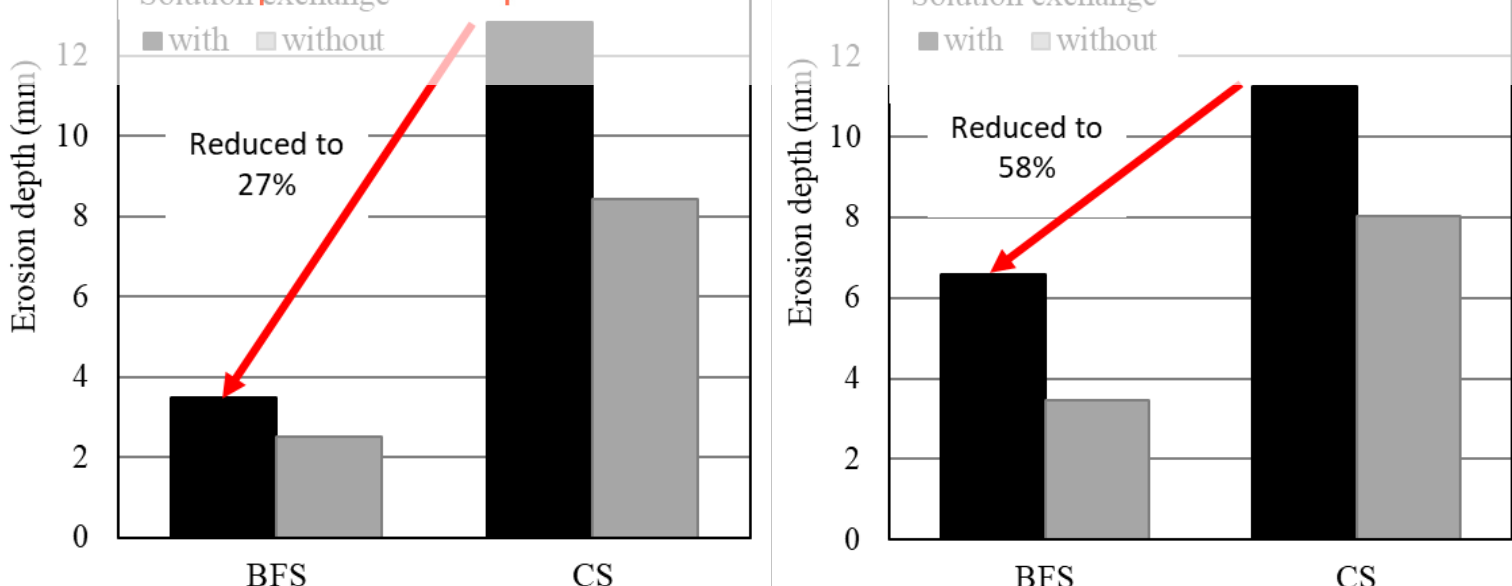

Figure 4. Results of the acid immersion test. 


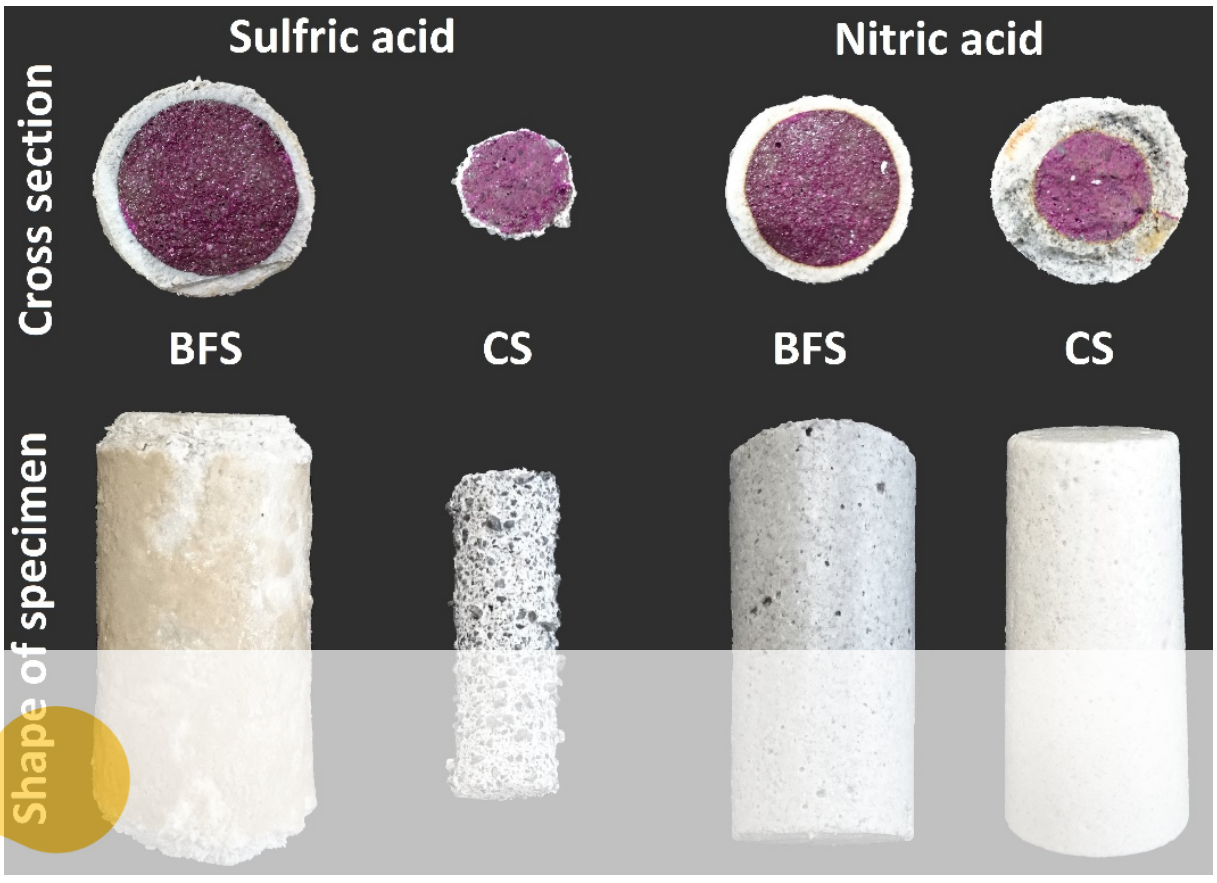

Figure 5. State after the acid immersion test (no-exchange).
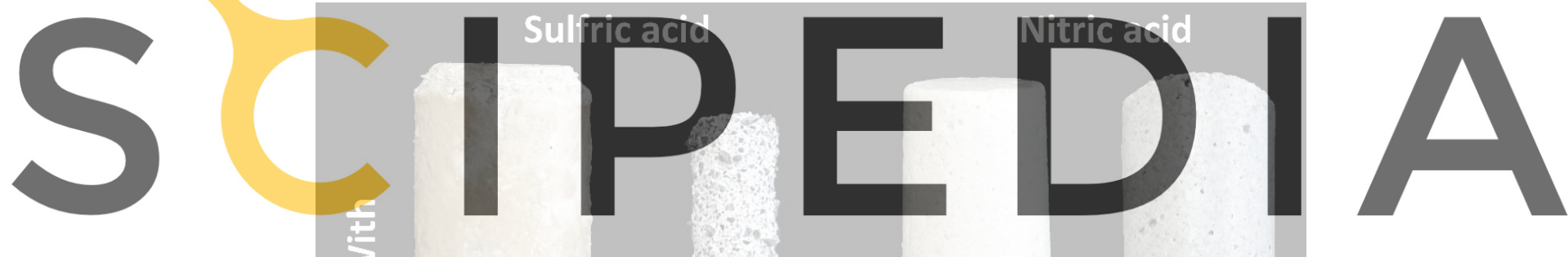

Register for free at https//www.scipedia.com to download the version without the watermark

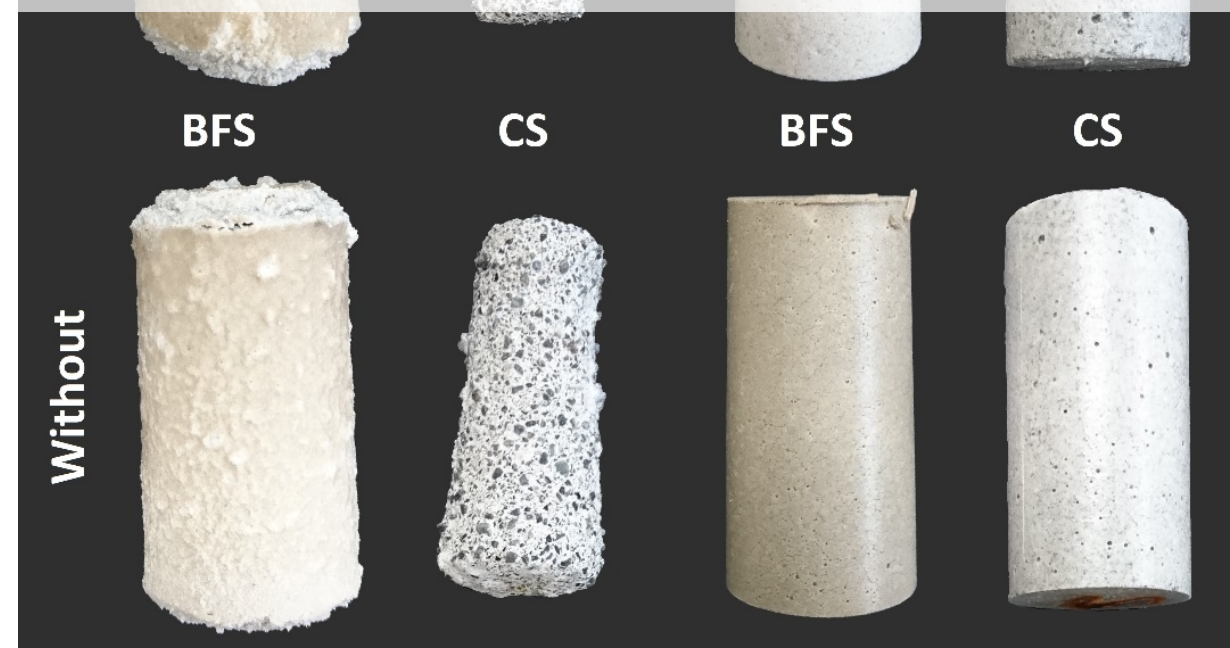

Figure 6. Shape of specimen after acid immersion test about solution exchange. 


\section{Conclusions}

It is well known that GBFS has different performance depending on the raw iron ore and process of steel mill (Tobo et al., 2015). However, few studies have evaluated the quality variation of GBFS. In this study, we examined a method that can easily determine the performance of GBFS. As a result, the following results were obtained from this study.

- The quality of GBFS sand as fine aggregate was evaluated by acid immersion test and F-T test in salt-water.

- The implementation of the F-T test evidently expressed the difference in durability depending on the reactivity of GBFS sand.

- Although leaching occurred during the F-T test by salt-water, it was found that destruction by F-T was superior to that by leaching. Or, even if leaching occurs, its effect is small when the liquid to solid ratio is 10 .

- Long-cured GBFS mortar had a significantly improved resistance to F-T.

- The sulfuric acid immersion test enabled the evaluation of the resistance of GBFS sand to sulfuric acid.

In the reaction with nitric acid, although GBFS sand mortar showed higher resistance than crushed sand mortar, it did not show special resistance like sulfuric acid immersion.

\section{Acknowledgements}

This study was conducted as part of normalization of JSCE-C 507 and JSCE-C 508. I would like to thank all the

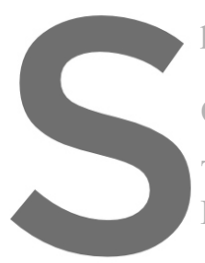

parties concerned, especially

ORCID

Takaya Kawato: http://orci

Kurashige: http://orcid.org/0000-0002-2773-0885
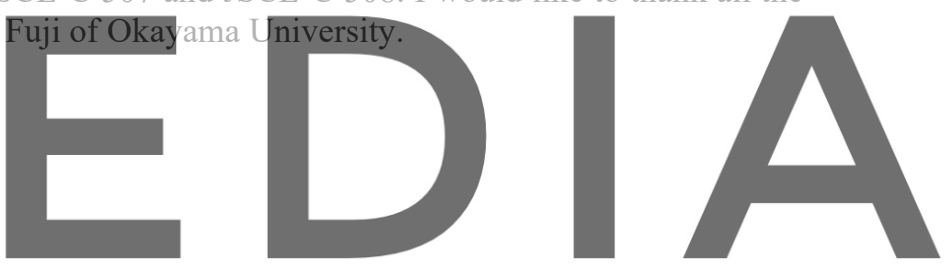

References

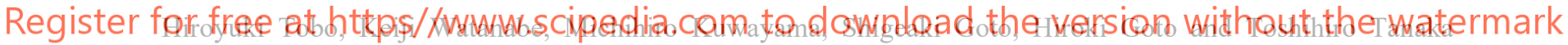
(2015). Effect of Water Granulation Conditions on Density and Grain Size of Granulated Blast Furnace Slag. ISIJ International, Vol. 55, No. 11, 2499-2508

Hitoshi Tanaka and Yoshihiro Masuda (2008). An experiment on progress of chemical corrosion of concrete by sulfuric acid and nitric acid. J. Struct. Const. Eng., AIJ, Vol.73 No.625, 355-361

JIS A 5011 (2013). Slag aggregate for concrete-Part 1: Blast furnace slag aggregate. Retrieved from http://kikakurui.com/a5/A5011-1-2013-01.html

Paweena Jariyathitipong, Kazuyoshi Hosotani, Takashi Fujii and Toshiki Ayano (2013). The sulfuric acid resistance of concrete with blast furnace slag. Proceeding of First International Conference on Concrete Sustainability (ICCS13),581-586

Paweena Jariyathitipong, Kazuyoshi Hosotani, Takashi Fujii and Toshiki Ayano (2013). Improvement of resistance to sulfuric acid attack of concrete by use of blast furnace slag sand. Journal of JSCE Ser. E Vol.69 No.4 337-347

Rakesh Kumar Patra and Bibhuti Bhusan Mukharjee (2018). Influence of granulated blast furnace slag as fine aggregate on properties of cement mortar. Advances in Concrete Construction, Vol. 6, No. 6, 611-629

Takahashi Katsunori, Watanabe Keiji, Niitani Kyoji, Hosotani Kazuyoshi (2018). Effect of Blast Furnace Slag Fine Aggregate for Freezing-and-Thawing Durability of Mortar and Concrete under Salt Existence Environment. JFE TECHNICAL REPORT No. 23

Toshiki Ayano and Takashi Fujii (2014). Resistance to freezing and thawing attack of concrete with blast furnace slag fine aggregate. Journal of JSCE Ser. E Vol.70, No.4, 417-427 